\title{
Rotational Angiography for 3D Roadmapping of Catheter Interventions in Congenital Heart Disease: Comparison of a Diagnostic and a Low Dose Program
}

\author{
Carolina Thoenes*, Robert Cesnjevar, Sven Dittrich, Martin Glöckler \\ Department of Pediatric Cardiology, University Hospital Erlangen, Erlangen, Germany \\ Email: *Carolina.Thoenes@gmx.de
}

Received 14 May 2016; accepted 6 August 2016; published 9 August 2016

Copyright $(2016$ by authors and Scientific Research Publishing Inc.

This work is licensed under the Creative Commons Attribution International License (CC BY). http://creativecommons.org/licenses/by/4.0/

\section{(c) (i) Open Access}

\begin{abstract}
Objectives: To compare the image quality, accuracy and effective dose of the default diagnostic program with the low dose program. Methods: The diagnostic and low dose programs of three-dimensional rotational angiography were compared considering their signal to noise ratio, their carrier to noise ratio and their actual radiation dose in $\mu \mathrm{Gy} \cdot \mathrm{m}^{2} / \mathrm{kg}$. An anthropomorphic phantom underwent both types of scans to evaluate the effective dose. Comparative measurements of vessel diameters were taken in the diagnostic and the low dose program and compared to the angiography as exact basis. The image quality of the scans using the different programs was rated by a specialist physician. Results: The low dose scan does use significantly less radiation and still provides images, which are adequate for 3D navigation of catheter-based interventions. Conclusion: Three-dimensional rotational angiography can be applied with the low dose program and is sufficient for 3D navigation.
\end{abstract}

\section{Keywords}

Three-Dimensional Imaging, Radiation Dosage, Low Dose Program, Diagnostic Dose Program

\section{Introduction}

Imaging modalities in the interventional cardiology have seen an impressive evolution and expansion [1]. The three-dimensional rotational angiography was developed in the mid-nineties and first has been used in neurora-

${ }^{*}$ Corresponding author.

How to cite this paper: Thoenes, C., Cesnjevar, R., Dittrich, S. and Glöckler, M. (2016) Rotational Angiography for 3D Roadmapping of Catheter Interventions in Congenital Heart Disease: Comparison of a Diagnostic and a Low Dose Program. Open Journal of Radiology, 6, 210-219. http://dx.doi.org/10.4236/ojrad.2016.63028 
diology [2]. In the past, using a conventional biplane angiography system, it was necessary to take single pictures in different C-Arm angulations with repetitive contrast admissions in order to receive a full image of the complex vascular anatomy [3]. By now in the so-called "flat-detector-computed tomography" the C-Arm rotates over a semicircle around the patient while contrast dye is applied. Out of the created volumetric data set a threedimensional rotational angiogram can be reconstructed. This technique allows 3-dimensional-guided catheter based interventions [3]. Until today the three-dimensional rotational angiography has been used for tumor embolization, image integration into fluoroscopy, for ablation therapy of arterial fibrillation and transcatheter valve implantations [4]-[6]. It has become the first-line screening technique providing decisive angioarchitectural information [7]. It has shown its usefulness in paediatric cases with congenital heart diseases [8]-[10]. Enabling 3D imaging during the intervention, the simplicity of the workflow, and the possibility to manipulate 3DRA images to define optimal projections to guide further catheter manipulations are advantages of this technique [11] [12]. Disadvantages are the use of contrast agent, the sensitivity to patient movement, the need for an invasive procedure, the fact that there were situations where there is a "drop-out" of the signal in specific areas and the high radiation dose [3] [8] [11] [13]-[15]. As an alternative to gain three-dimensional images in patients with congenital heart diseases, three-dimensional MRI, three-dimensional CT and the three-dimensional TEE can be used [12]. To justify the further use of the three-dimensional rotational angiography its radiation dose has to be minimized. There is always a possibility to reduce radiation, for example by using a low dose program. We would like to know whether the use of this low dose program is sufficient enough for the 3D roadmapping of catheter interventions in congenital heart diseases.

\section{Material and Methods}

In a period of 58 months starting January of 2010 until October 2014 a total of 483 patients underwent the three dimensional rotational angiography at our facility. As those patients covered the whole spectrum of congenital heart diseases, this three dimensional rotational angiography was performed in a range of locations, suiting the individual case. In the first phase 381 patients underwent the diagnostic dose scan, which uses $0.36 \mu$ Gy per image. Later, in the second phase, a group of 102 patients underwent the low dose version, which uses $0.1 \mu$ Gy per image. Demographic data are listed in Table 1. The 3DRA was performed interventional and followed by a control angiography. No breath holding was performed during the 3DRA acquisitions. Images were done using a flat detector CT with a biplane angiography system equipped with two $20 \times 20 \mathrm{~cm}^{2}$ flat panel detectors using a $960 \times 960$ matrix (Axiom Art is, Siemens Medical Solutions, Forchheim, Germany). For the diagnostic program image acquisition was performed with a dose of $0.36 \mu \mathrm{Gy}$ per image (30 images per second, scanning time $5 \mathrm{sec}$.) with a fixed tube voltage of $90 \mathrm{kV}$ and automatically adapted tube current. For the low dose program the FD-CT was performed using a dose of $0.1 \mu \mathrm{Gy}$ per image (30 images per second, scanning time $5 \mathrm{sec}$.) in addition to a 0.2 $\mathrm{mm}$ copper filter and an adapted tube voltage of $70 \mathrm{kV}$. The anti-scatter grid was removed in patients $<20 \mathrm{~kg}$.

Table 1. Demographic data of the entire cohort.

\begin{tabular}{ccccc}
\hline Parameter & All & 30/5s DRc & 30/5s DR-L & p-value \\
\hline Number & 483 & 381 & 102 & 0.6132 \\
Gender (m/f) & $282 / 201$ & $220 / 161$ & $62 / 40$ & $<0.0001$ \\
Age (years) & $2.83(0-42.55)$ & $2.51(0-42.53)$ & $6.0(0-42.55)$ & 0.0002 \\
Height (cm) & $92(45-191)$ & $90(45-191)$ & $95(49-191)$ & 0.0002 \\
Weight (kg) & $12.8(2.3-108)$ & $12(2.3-98)$ & $20.55(3.01-108)$ & 0.0001 \\
Total contrast agent used (ml) & $67(5-256)$ & $62(5-256)$ & $89(10-240)$ & $33(7-67)$ \\
Contrast agent used in the 3DRA (ml) & $24(0-76)$ & $22(0-76)$ & 0.0272 \\
\hline
\end{tabular}

Legend: This table shows the demographic date of the all the patients, the fraction of patients undergoing the diagnostic dose scan (30/5s DRc) and the fraction of patients undergoing the low dose scan (30/5s DR-L). Shown are the number or the median and the range. The results were compared with a nonparametric Mann-Whitney U-test giving the p-value. (30/5s DRc: diagnostic dose program; 30/5s DR-L: low dose program; m/f: male/female; cm: centimeter; kg: kilogram; ml: milliliter; 3DRA: three dimensional rotational angiography). 
Cross-sectional images were created with $0.4 \mathrm{~mm}$ thickness in a $500 \times 500$ matrix formats. Imeron ${ }^{\circledR} 350$ (Iodine $350 \mathrm{mg} / \mathrm{ml}$; Bracco Imaging Deutschland $\mathrm{GmbH}$ ) was used as contrast agent, which always was diluted using saline in a concentration of median $40 \%$ (range $25 \%$ - 60\%). A scan was post processed on a commercially available workstation (Leonardo, Siemens Healthcare, Forchheim, Germany). All measurements made on the rotational angiography images were measured in reconstructed multiplanar reconstruction 3D images in native windowing. The device used for the measurements was syngo.via (Siemens Medical solutions, Forchheim, Germany). The results we achieved were compared with a nonparametric Mann-Whitney U-test giving the p-value to show the significance. For the statistic calculations the add-in Analyse-it for Microsoft Excel was used (Analyse-it Software, Ltd., Leeds, Great Britain). To compare the image noise three groups of patients were formed. Each group consists out of twenty patients and differs in the location where the contrast agent was applied. From those twenty patients per group, ten underwent the diagnostic scan and then the low dose version. We took those cases out of our pool of 483 patients. The demographic data for those groups are in Table 2. They had to fulfill certain criteria as listed in Table 3 . The image noise was measured in a contrasted vessel. This

Table 2. Demographic data for the patients used for the signal to noise and carrier to noise measurements.

\begin{tabular}{cccc}
\hline Parameter & All & $30 / 5$ s DRc & $30 / 5$ s DR-L \\
Number & 60 & 30 & 30 \\
Pulmonary group: gender (m/f) & $7 / 13$ & $3 / 7$ & $2.195(0.76-14.31)$ \\
Pulmonary group: age (years) & $2.195(0.4-14.31)$ & $2.515(0.4-13.82)$ & $12.25(7.6-53.2)$ \\
Pulmonary group: weight (kg) & $11.6(5.75-53.2)$ & $10.45(5.75-47)$ & $55.5(27-169)$ \\
Pulmonary group: total contrast agent used (ml) & $58(27-169)$ & $62.75(38-147)$ & $19.5(12-45)$ \\
Pulmonary group: contrast agent used in the 3DRA (ml) & $19.5(12-45)$ & $19.5(14-36)$ & $7 / 3$ \\
Aortic group: gender (m/f) & $14 / 6$ & $7 / 3$ & $47.55(9.2-72)$ \\
Aortic group: age (years) & $11.78(0.25-22.18)$ & $10.69(0.25-22.18)$ & $97.5(40-172)$ \\
Aortic group: weight (kg) & $40.5(4.3-72)$ & $30.5(4.32-65.8)$ & $36(18-45)$ \\
Aortic group: total contrast agent used (ml) & $97.5(21-172)$ & $88(21-164)$ & $19.52)$ \\
Aortic group: contrast agent used in the 3DRA (ml) & $36(10-58)$ & $37.5(10-58)$ & $7 / 4$ \\
Glenn group: gender (m/f) & $13 / 7$ & $7 / 3$ & $18.89(0.35-4.36)$ \\
Glenn group: age (years) & $1.125(0.25-4.36)$ & $0.825(0.25-2.61)$ & $12.1(4.56-14.2)$ \\
Glenn group: weight (kg) & $11.05(4-14.2)$ & $10.1(4-13.7)$ & $59(19-98)$
\end{tabular}

Legend: The demographic data for the comparison groups of the signal to noise and carrier to noise measurements for the diagnostic program (30/5s DRc) and the low dose program (30/5s DR-L). Shown are the number or the median with range. (30/5s DRc: diagnostic dose program; 30/5s DR-L: low dose program; m/f: male/female; kg: kilogram; ml: milliliter; 3DRA: three dimensional rotational angiography).

Table 3. Criteria and location of the image noise measurements.

\begin{tabular}{|c|c|c|c|}
\hline Parameter & Criteria & $1^{\text {st }}$ measurement & $2^{\text {nd }}$ measurement \\
\hline Pulmonary Group & $\begin{array}{l}\text { Contrast agent was } \\
\text { injected into the pulmonary artery }\end{array}$ & $\begin{array}{l}\text { Mean value at the } \\
\text { hilus of the pulmonary artery }\end{array}$ & $\begin{array}{l}\text { Mean value of the } \\
\text { autochthonic back muscles }\end{array}$ \\
\hline Aortic Group & $\begin{array}{l}\text { Contrast agent was } \\
\text { injected into the aortic arch }\end{array}$ & $\begin{array}{l}\text { Mean value in } \\
\text { the descending aorta }\end{array}$ & $\begin{array}{l}\text { Mean value of the } \\
\text { autochthonic back muscles }\end{array}$ \\
\hline Glenn Group & $\begin{array}{l}\text { Contrast agent was } \\
\text { injected into the Glenn anastomosis }\end{array}$ & $\begin{array}{l}\text { Mean value within } \\
\text { the Glenn anastomosis }\end{array}$ & $\begin{array}{l}\text { Mean value of the } \\
\text { autochthonic back muscles }\end{array}$ \\
\hline
\end{tabular}

Legend: Criteria and location of the image noise measurements for the three different groups of patients: the Pulmonary Group, the Aortic Group and the Glenn Group. 
vessel was the pulmonary artery, the aortic arch or the Glenn anastomosis (Table 3). The images noise was measured within a 1 square $\mathrm{cm}$ field. Out of these measurements the signal to noise ratio and the carrier to noise ratio were calculated. The signal to noise ratio can be achieved by dividing the image noise mean value through the air standard deviation. The carrier to noise ratio can be calculated by subtracting the image noise mean value of the autochthonic back muscles from the image noise mean value in the vessel and then dividing the result by the standard deviation of the air. To achieve the effective radiation dose a pediatric anthropomorphic phantom type "Stanley Atom" underwent both types of programs. The phantom contained 200 thermoluminescent dosimeters. The readout of those dosimeters was done according to a standard procedure [16]. The mean values of the dosimeters lead to our organ doses. The effective dose than was calculated by summarizing the weighted organ doses. This was done in compliance with the International Commission on Radiological Protection 103 guidelines [17]. Radiation dose and the irradiated area were measured in the collimator housing, independent from the patient distance [18]. Out of these system reported doses the radiation dose in $\mu \mathrm{Gym}^{2} / \mathrm{kg}$ was calculated for the 483 cases and compared between the diagnostic program and the low dose program. To identify the accuracy of both programs two comparable groups of each ten patients were created. One group consisted out of patients undergoing the diagnostic scan and the others were scanned with the low dose program. Four different diameters of vessels in each scan were measured and later compared to the diameter of the same vessel measured in the control angiography. For the demographic data and location of the measurements see Table 4 and Table 5. The measurements were made at the end of the $\mathrm{P}$ wave. The differences in the measurements between the scan and the angiography were evaluated for both groups. For the image quality we created one last group of 14 patients consisting out of seven comparable couples (Table 6). Of each pair one underwent the diagnostic program and one the low dose version. An expert operator compared those scans. The expert operator did not know which scan was performed by the diagnostic program and which scan was done by the low dose version.

\section{Results}

The mean value and the standard deviation of the signal to noise ratio are higher in the images created by a low dose scan. For the carrier to noise ratio the mean value is higher in the low-dose images in the Pulmonary and the Glenn Group but not in the Aortic Group. For the carrier to noise ratio the standard deviation ranked higher in the low dose scans (Table 7). In the anthropomorphic phantom for newborns (type Stanley Atom) the effective dose was reduced in male bodies from $0.1 \mathrm{mSv}$ running a diagnostic scan to $0.03 \mathrm{mSv}$ for a male and 0.04 $\mathrm{mSv}$ for a female phantom running the low dose scan. The 30/5s DR-L program uses significantly less radiation than the 30/5s DRc program ( $\mathrm{P}<0.0001$; non parametric Mann-Whitney U-test). Mean value and standard deviation of both programs can be seen in Table 8 . The accuracy of the diagnostic program is higher than the accuracy of the low-dose program (Figure 1(a) and Figure 1(b)). Comparing the seven couples showed in two cases that the partner with the low dose scan offered better image quality, in another two cases the difference was minimal, and in three couples the partner undergoing the high dose scan had better pictures to deliver. Even the lowest quality picture could still be used for the intervention (Figure 2).

\section{Discussion}

Less than half of the original radiation dose is possible using a low dose program in pediatrics (Table 8). The

Table 4. Demographic data of the patients used for the accuracy measurements.

\begin{tabular}{cccc}
\hline Parameter & All & $30 / 5$ sRc & $30 / 5$ s DR-L \\
\hline Number & 20 & 10 & 10 \\
Gender (m/f) & $12 / 8$ & $6 / 4$ & $6 / 4$ \\
Age (years) & $8.12(0.11-22.79)$ & $6.69(0.11-22.79)$ & $8.29(0.78-21.17)$ \\
Weight (kg) & $17.6(3.1-74.5)$ & $9.9(3.1-65.8)$ & $24.25(6.13-74.5)$ \\
Total contrast agent used (ml) & $78(11-169)$ & $72(11-136)$ & $87.5(27-169)$ \\
Contrast agent used in the 3DRA (ml) & $28.5(7-45)$ & $27(7-42)$ & $30(14-45)$ \\
\hline
\end{tabular}

Legend: The demographic data are shown for the group as whole, the patients undergoing a diagnostic scan (30/5s DRc) and the patients undergoing a low dose scan (30/5s DR-L). Number and median with range are shown. (30/5s DRc: diagnostic dose program; 30/5s DR-L: low dose program; m/f: male/female; kg: kilogram; ml: milliliter; 3DRA: three dimensional rotational angiography). 
Table 5. Measurement locations.

\begin{tabular}{|c|c|c|c|c|c|c|}
\hline ient & Scan & $\begin{array}{l}\text { Injection of } \\
\text { contrast agent }\end{array}$ & st measurement & nd measurement & 3rd measurement & th measurement \\
\hline 13 & 30/5s DR-L & Aortic arch & $\begin{array}{l}1^{\text {st }} \text { vessel } \\
\text { leaving the aortic arch }\end{array}$ & $\begin{array}{l}2^{\text {nd }} \text { vessel } \\
\text { leaving the aortic arch }\end{array}$ & $\begin{array}{l}3^{\text {rd }} \text { vessel } \\
\text { leaving the aortic arch }\end{array}$ & ta \\
\hline 23 & 30/5s DR-L & Aorti & $\begin{array}{l}1^{\text {st }} \text { vessel } \\
\text { leaving the aortic arch }\end{array}$ & $\begin{array}{l}2^{\text {nd }} \text { vessel } \\
\text { leaving the aortic arch }\end{array}$ & $\begin{array}{l}3^{\text {rd }} \text { vessel } \\
\text { leaving the aortic arch }\end{array}$ & ta \\
\hline 33 & 30/5s DR-L & Aortic & $\begin{array}{l}1^{\text {st }} \text { vessel } \\
\text { leaving the aortic arch }\end{array}$ & $\begin{array}{l}2^{\text {nd }} \text { vessel } \\
\text { leaving the aortic arch }\end{array}$ & $\begin{array}{l}3^{\text {rd }} \text { vessel } \\
\text { leaving the aortic arch }\end{array}$ & ta \\
\hline 43 & 30/5s DR-L & Aortic & $\begin{array}{l}1^{\text {st }} \text { vessel } \\
\text { leaving the aortic arch }\end{array}$ & $\begin{array}{l}2^{\text {nd }} \text { vessel } \\
\text { leaving the aortic arch }\end{array}$ & $\begin{array}{l}3^{\text {rd }} \text { vessel } \\
\text { leaving the aortic arch }\end{array}$ & aorta \\
\hline 53 & 30/5s DR-L & Aorti & $\begin{array}{l}1^{\text {st }} \text { vessel } \\
\text { leaving the aortic arch }\end{array}$ & $\begin{array}{l}2^{\text {nd }} \text { vessel } \\
\text { leaving the aortic }\end{array}$ & leaving $t$ & Des \\
\hline 63 & \multicolumn{3}{|c|}{ 30/5s DR-LRight pulmonary arteryRight pulmonary artery } & Right hilus & \multicolumn{2}{|c|}{ Upper right periphery Lower right periphery } \\
\hline 73 & \multicolumn{3}{|c|}{ 30/5s DR-LRight pulmonary arteryRight pulmonary artery } & & \multicolumn{2}{|c|}{ Upper right periphery Lower right periphery } \\
\hline 83 & \multicolumn{3}{|c|}{ 30/5s DR-LRight pulmonary arteryRight pulmonary artery } & Right hilus & \multicolumn{2}{|c|}{ Upper right periphery Lower right periphery } \\
\hline 93 & 30/5s DR-L & Right ventricle & Right pulmonary artery & Right hilus & \multicolumn{2}{|c|}{ Upper right periphery Lower right periphery } \\
\hline 103 & 30/5s DR-L & Right ventricle & Right pulmonary artery & Right hilus & \multicolumn{2}{|c|}{ Upper right periphery Lower right periphery } \\
\hline 1 & 30/5s DRc & Aorti & $\begin{array}{l}1^{\text {st }} \text { vessel } \\
\text { leaving the aortic arch }\end{array}$ & $\begin{array}{l}2^{\text {nd }} \text { vessel } \\
\text { leaving the aortic arch }\end{array}$ & $\begin{array}{l}3^{\text {rd }} \text { vessel } \\
\text { leaving the aortic arch }\end{array}$ & Des \\
\hline 2 & 30/5s DRc & Aortic & $\begin{array}{l}1^{\text {st }} \text { vessel } \\
\text { leaving the aortic arch }\end{array}$ & $\begin{array}{c}2^{\text {nd }} \text { vessel leaving the aortic } \\
\text { arch }\end{array}$ & $\begin{array}{r}3^{\text {rd }} \\
\text { leaving th }\end{array}$ & Descending \\
\hline 3 & 30/5s DRc & Aortic arch & $\begin{array}{l}1^{\text {st }} \text { vessel } \\
\text { leaving the aortic arch }\end{array}$ & $\begin{array}{l}2^{\text {nd }} \text { vessel } \\
\text { leaving the aortic arch }\end{array}$ & $\begin{array}{l}\text { ssel } \\
\text { aortic arch }\end{array}$ & Desc \\
\hline 4 & 30/5s DRc & Aortic arch & $\begin{array}{c}1^{\text {st }} \text { vessel } \\
\text { leaving the aortic arch }\end{array}$ & $\begin{array}{l}2^{\text {nd }} \text { vessel } \\
\text { leaving the aortic arch }\end{array}$ & leaving th & Descending aorta \\
\hline 5 & $30 / 5 s$ DRc & Aort & $\begin{array}{c}1^{\text {st }} \text { vessel } \\
\text { leaving the aortic arch }\end{array}$ & $\begin{array}{l}2^{\text {nd }} \text { vessel } \\
\text { leaving the aortic arch }\end{array}$ & $\begin{array}{c}3^{\text {rd }} \text { vessel } \\
\text { leaving the aortic arch }\end{array}$ & Descending aorta \\
\hline 6 & \multicolumn{3}{|c|}{ 30/5s DRc Right pulmonary arteryRight pulmonary artery } & ight bilus & \multicolumn{2}{|c|}{ Upper right periphery Lower right periphery } \\
\hline 7 & \multicolumn{3}{|c|}{ 30/5s DRc Right pulmonary arteryRight pulmonary artery } & & \multicolumn{2}{|c|}{ Upper right periphery Lower right periphery } \\
\hline 8 & \multicolumn{3}{|c|}{ 30/5s DRc Right pulmonary arteryRight pulmonary artery } & Right hilus & \multicolumn{2}{|c|}{ Upper right periphery Lower right periphery } \\
\hline 9 & 30/5s DRc & Right ventricle & Right pulmonary artery & & \multicolumn{2}{|c|}{ Upper right periphery Lower right periphery } \\
\hline 10 & 30/5s DRc & Right ventricle & Right pulmonary artery & Right hilus & \multicolumn{2}{|c|}{ Upper right periphery Lower right periphery } \\
\hline
\end{tabular}

Legend: Locations, where the diameters of the vessels were measured to compare a low dose scan (30/5s DR-L) or a diagnostic dose scan (30/5s DRc) to the matching angiography. Here, the location for the low dose and the diagnostic dose patients can be seen. In the angiography the diameter was measured at the matching location, which is why they are no listed again. The location where the contrast agent was injected can be seen as well. (30/5s DRc: diagnostic dose program; 30/5s DR-L: low dose program).

Table 6. Demographic data of the patients used for the image quality.

\begin{tabular}{|c|c|c|c|}
\hline Parameter & All & 30/5s DRc & 30/5s DR-L \\
\hline Number & 14 & 7 & 7 \\
\hline Gender (m/f) & $10 / 4$ & $6 / 1$ & $4 / 3$ \\
\hline Age (years) & $12.42(0.09-26.04)$ & $11.24(0.36$ - 26.04) & $13.6(0.09-18.02)$ \\
\hline Weight (kg) & $40.5(3.7-60)$ & $41(3.8-59)$ & $40(3.7-60)$ \\
\hline Total contrast agent used (ml) & $79(21-154)$ & $56(21-108)$ & $97(39-154)$ \\
\hline Contrast agent used for the 3DRA (ml) & $35(7-58)$ & $34(10-58)$ & $36(7-42)$ \\
\hline
\end{tabular}

Legend: This table presents the demographic data for the patients of which the scans were compared by an expert operator. Number or median with range are shows for the group as whole, the fraction of patients undergoing the diagnostic dose scan (30/5s DRc) and the fraction of patients undergoing the low dose scan (30/5s DR-L). (30/5s DRc: diagnostic dose program; 30/5s DR-L: low dose program; m/f: male/female; kg: kilogram; ml: milliliter; 3DRA: three dimensional rotational angiography). 
Table 7. Results of the signal to noise and carrier to noise measurements.

\begin{tabular}{|c|c|c|c|c|c|c|}
\hline Parameter & $\begin{array}{c}\text { Pulmonary Group: } \\
\text { SNR }\end{array}$ & $\begin{array}{l}\text { Aortic Group: } \\
\text { SNR }\end{array}$ & $\begin{array}{c}\text { Glenn Group: } \\
\text { SNR }\end{array}$ & $\begin{array}{c}\text { Pulmonary Group: } \\
\text { CNR }\end{array}$ & $\begin{array}{c}\text { Aortic Group: } \\
\text { CNR }\end{array}$ & $\begin{array}{c}\text { Glenn Group: } \\
\text { CNR }\end{array}$ \\
\hline 30/5s DRc & $19.04 \pm 5.88$ & $22.02 \pm 8.21$ & $32.40 \pm 13.20$ & $16.34 \pm 6.67$ & $19.15 \pm 6.72$ & $28.40 \pm 11.66$ \\
\hline 30/5s DR-L & $19.33 \pm 8.92$ & $23.46 \pm 11.15$ & $33.05 \pm 17.07$ & $17.38 \pm 8.83$ & $18.84 \pm 10.90$ & $29.24 \pm 16.91$ \\
\hline p-value & 0.7959 & 0.9118 & 0.8535 & 0.9705 & 0.6305 & 0.3527 \\
\hline
\end{tabular}

Legend: The calculated mean value and standard deviation of the signal to noise ratio (SNR) and carrier to noise ratio (CNR) of each of the three groups: Pulmonary Group, Aortic Group, Glenn Group. 30/5s DRc indicates that the diagnostic dose version was used. 30/5s DR-L stands for the low dose program. Results compared with a nonparametric Mann-Whitney U-test, P = 0.8592/0.5346 for SNR/CNR. (30/5s DRc: diagnostic dose program; 30/5s DR-L: low dose program; SNR: signal to noise ratio; CNR: carrier to noise ratio).

Table 8. The radiation dose of the diagnostic and the low dose program compared.

\begin{tabular}{|c|c|c|c|}
\hline & 30/5s DRc & 30/5s DR-L & p-value \\
\hline Mean value & 8.1 & 2.3 & $<0.0001$ \\
\hline Standard deviation & 4.51 & 1.53 & \\
\hline Maximum & 61.77 & 9.87 & \\
\hline Minimum & 0.0 & 0.46 & \\
\hline Median & 7.26 & 1.82 & \\
\hline 3rd quartile & 9.33 & 2.98 & \\
\hline 1st quartile & 5.61 & 1.37 & \\
\hline
\end{tabular}

Legend: This table compares the used radiation dose in $\mu \mathrm{Gym}^{2} / \mathrm{kg}$ of the entire cohort of clinical scans both the diagnostic dose (30/5s DRc) and the low dose program (30/5s DR-L). Results compared with a nonparametric Mann-Whitney U-test, p < 0.0001. (30/5s DRc: diagnostic dose program; 30/5s DR-L: low dose program).

mean radiation dose was reduced by $71.6 \%$. Still enough image quality remained so that the images could be used. In 2015 Peters et al. published a median effective dose of three dimensional rotational angiography in children of $1.6 \mathrm{mSv}$, which can be more than halved to $0.6 \mathrm{mSv}$, by applying frame reduction from 248 to 133 frames per rotation [19]. We did not alternate our frames but we reduced the amount of $\mu \mathrm{Gym}$ per image, added a $0.2 \mathrm{~mm}$ copper filter and reduced the tube voltage to $70 \mathrm{kV}$. Peters et al. used the Monte Carlo PCXMC 2.0 method, a computer program calculating organ doses and effective doses [19]. We measured the radiation dose in a phantom and then calculated the effective dose. The effective dose was $0.03 \mathrm{mSv}$ for a male and $0.04 \mathrm{mSv}$ for a female phantom when running the low dose scan. We did not use contrast agent in this scan. This might be one reason for our low effective dose value. Using contrast agent would increase the effective dose as automatic exposure control would increase the radiation to achieve a better contrast in the images. The signal to noise and carrier to noise ratio turned out better in the low dose scans than it did in the diagnostic version. Both ratios show how good a signal can be distinguished from the background. It is a physical principle that a program using less $\mathrm{kV}$ leads to the fact that differences in density can be seen better. Therefore the result is a higher signal and carrier to noise ratio [20]. The reason, why in the Aortic Group the carrier to noise ratio ranks lower in the low dose program, might simply be that the number of examined cases was limited. Our results show that a reduction in radiation did not lead to a significant change in the image quality $(P=0.8592 / 0.5346$ for SNR/CNR; non parametric Mann-Whitney-U-test). To compare the accuracy of the two programs we compared the diameter of the vessels of the diagnostic and the low dose program to the diameters of the same vessels in a biplane angiography. We found a mean difference of $6 \%$ comparing the low dose scans with an angiography, and a mean difference of $2.74 \%$ when comparing the diagnostic dose scan with the angiography. Consequently the diagnostic scan is more accurate. Wielandts et al. did compare a low radiation dose left ventricular multi-phase rotational angiography (4DRA) with a biplane left ventricle angiography. Of the distances between the measured contours, 95\% were $<4 \mathrm{~mm}$ in both incidences. Here was a high accuracy shown between the 4DRA and the angiography [21]. However we measured different vessels that are not as easy to access as the left ventricle. The effective radiation dose for 4DRA, calculated by patient-specific Monte-Carlo simulation, was $5.1 \pm 1.1 \mathrm{mSv}$ in Wielandts study [21]. De Buck et al. state that three-dimensional rotational angiography is possible with a 


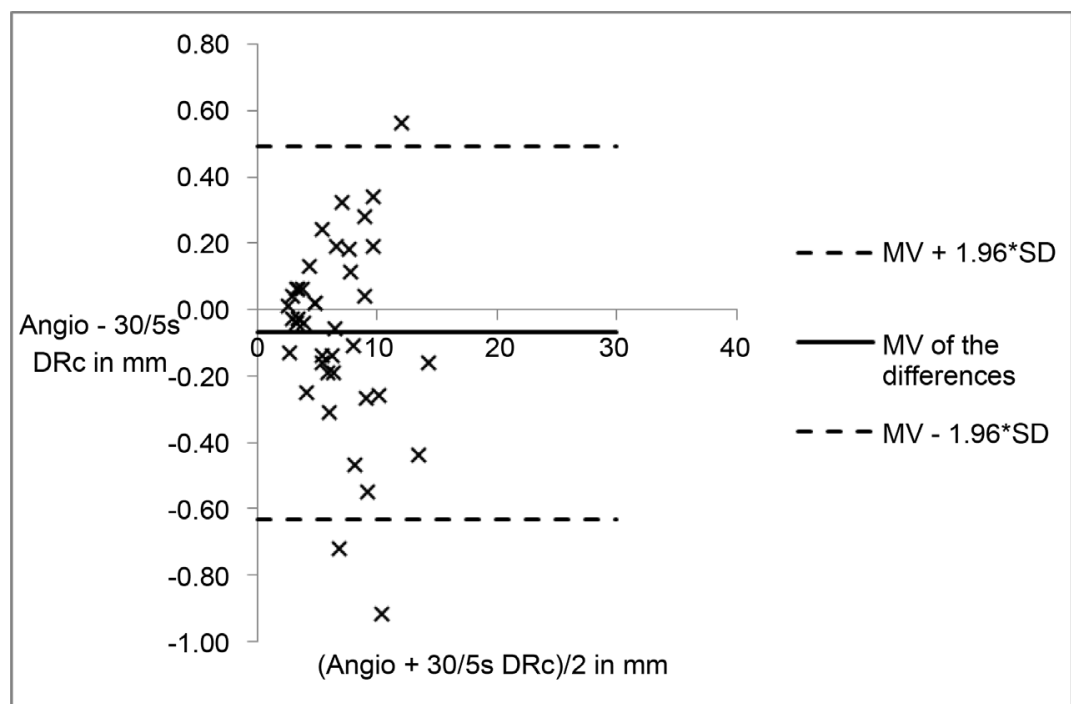

(a)

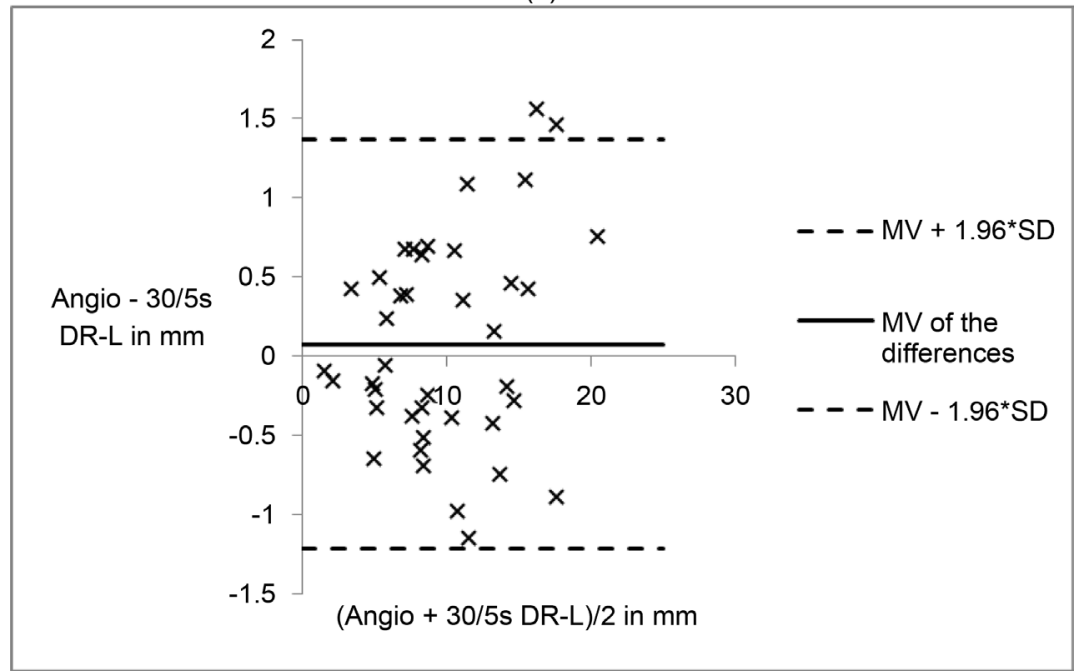

(b)

Figure 1. (a) Comparing the accuracy of the diagnostic dose program with the angiography. Bland-Altman plot comparing the diagnostic scan (30/5s DRc) and angiography (Angio) measurements. The diagram shows the mean value (MV) and the mean value \pm the standard deviation (SD) which has been multiplied by 1.96. (b) Comparing the accuracy of the low-dose program with the angiography. Bland-Altman plot comparing the low dose scan (30/5s DR-L) and angiography (Angio) measurements. The diagram shows the mean value (MV) and the mean value \pm the standard deviation (SD) which has been multiplied by 1.96. (30/5s DRc: diagnostic dose program; 30/5s DR-L: low dose program; Angio: angiography; mm: millimeter; MV: mean value; SD: standard deviation).

significant reduction in the effective dose without compromising image quality [11]. To reduce the effective dose they dropped the frame rate from 248 to 67 and 45 frames. Their measurements were done on 60 patients instead of a phantom. They also used the Monte Carlo system to calculate their effective dose. To evaluate the image quality they used the criteria overall image quality, noise, artefacts, and visualization of specific anatomical structures. We rated our scans with regard on the tidiness of the visible structure, the clarity of the edges, the noise, and the artefacts. Our results were that images taken with a low dose program were not always as good in quality and as accurate as high dose images. Compromises in images quality had to be made. But all our images were rated as at least useful.

\section{Conclusion}

Three-dimensional rotational angiography can be worked in the low dose program without a major loss of image 


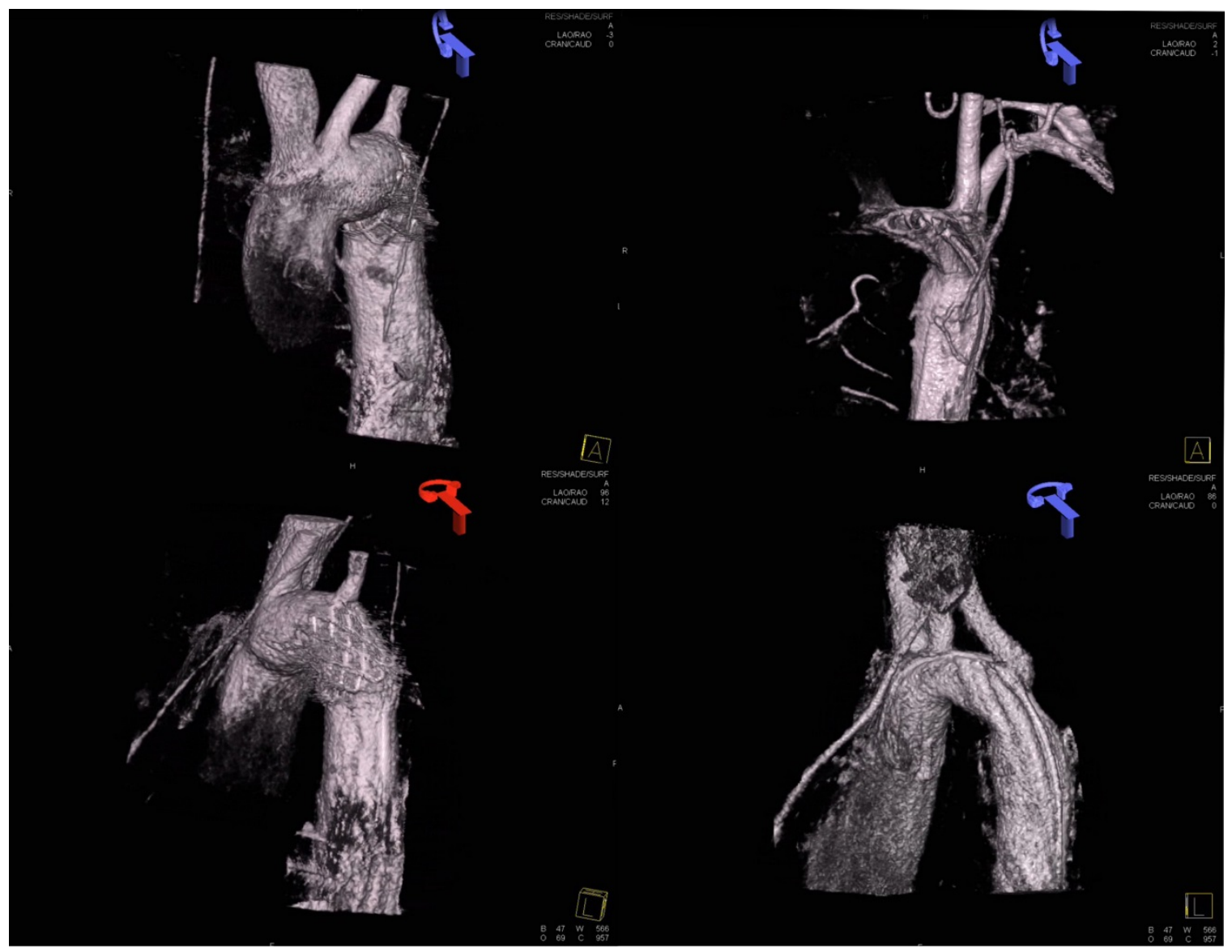

Figure 2. This image shows four scans. The two scans on the left were done using the diagnostic dose program. The two images on the right are scans of comparable patients that were done using the low dose program.

quality. In this way the burden of the radiation for the patient can be significantly reduced compared to the default of $8.1 \mu \mathrm{Gy} \cdot \mathrm{m}^{2} / \mathrm{kg}$ in the diagnostic version. The scans by the low dose program are helpful in 3D navigation. Therefore we suggest using the low dose program instead of the diagnostic version from now on.

\section{Acknowledgements}

The authors of this manuscript declare relationships with the following companies: Siemens Healthcare. The authors state that this work has not received any funding. The present work was performed in fulfillment of the requirements for obtaining the degree "Dr. med." at the Friedrich-Alexander-University Erlangen-Nürnberg (FAU).

\section{References}

[1] Schwartz, J.G., Neubauer, A.M., Fagan, T.E., Noordhoek, N.J., Grass, M. and Carroll, J.D. (2011) Potential Role of Three-Dimensional Rotational Angiography and C-Arm CT for Valvular Repair and Implantation. The International Journal of Cardiovascular Imaging, 27, 1205-1222. http://dx.doi.org/10.1007/s10554-011-9839-9

[2] Castano-Duque, C.H., Ruscalleda-Nadal, J., de Juan-Delago, M., Guardia-Mas, E., San Roman-Manzanera, L., Bartomeus-Jene, F., Molet-Teixido, J., Tresserras-Ribo, P., Pares-Munoz, P. and Clavel Laria, P. (2002) Early Experience Studying Cerebral Aneurysms with Rotational and Three-Dimensional Angiography and Review of CT and MR Angiography Literature. Interventional Neuroradiology, 8, 377-391.

[3] Glockler, M., Halbfabeta, J., Koch, A., Achenbach, S. and Dittrich, S. (2013) Multimodality 3D-Roadmap for Cardiovascular Interventions in Congenital Heart Disease-A Single-Center, Retrospective Analysis of 78 Cases. Catheterization and Cardiovascular Interventions, 82, 436-442. http://dx.doi.org/10.1002/ccd.24646

[4] Meyer, B.C., Frericks, B.B., Albrecht, T., Wolf, K.J. and Wacker, F.K. (2007) Contrast-Enhanced Abdominal Angiographic CT for Intra-Abdominal Tumor Embolization: A New Tool for Vessel and Soft Tissue Visualization. Cardi- 
oVascular and Interventional Radiolog, 30, 743-749. http://dx.doi.org/10.1007/s00270-007-9029-2

[5] Nolker, G., Gutleben, K.J., Marschang, H., Ritscher, G., Asbach, S., Marrouche, N., Brachmann, J. and Sinha, A.M. (2008) Three-Dimensional Left Atrial and Esophagus Reconstruction Using Cardiac C-Arm Computed Tomography with Image Integration into Fluoroscopic Views for Ablation of Atrial Fibrillation: Accuracy of a Novel Modality in Comparison with Multislice Computed Tomography. Heart Rhythm, 5, 1651-1657. http://dx.doi.org/10.1016/j.hrthm.2008.09.011

[6] Walther, T., Schuler, G., Borger, M.A., Kempfert, J., Seeburger, J., Ruckert, Y., Ender, J., Linke, A., Scholz, M., Falk, V. and Mohr, F.W. (2010) Transapical Aortic Valve Implantation in 100 Consecutive Patients: Comparison to Propensity-Matched Conventional Aortic Valve Replacement. European Heart Journal, 31, 1398-1403. http://dx.doi.org/10.1093/eurheartj/ehq060

[7] Ferre, J.C., Niederberger, E., Morandi, X., Raoult, H., Carsin-Nicol, B. and Gauvrit, J.Y. (2013) Anatomical Variations of the Anterior Cerebral Arterial Circle Visualized by Multidetector Computed Tomography Angiography: Comparison with 3D Rotational Angiography. Journal of Neuroradiology, 40, 112-120. http://dx.doi.org/10.1016/j.neurad.2012.05.009

[8] Glatz, A.C., Zhu, X., Gillespie, M.J., Hanna, B.D. and Rome, J.J. (2010) Use of Angiographic CT Imaging in the Cardiac Catheterization Laboratory for Congenital Heart Disease. JACC Cardiovasc Imaging, 3, 1149-1157. http://dx.doi.org/10.1016/j.jcmg.2010.09.011

[9] Rigatelli, G., Zamboni, A. and Cardaioli, P. (2007) Three-Dimensional Rotational Digital Angiography in a Complicated Case of Patent Ductus Arteriosus Transcatheter Closure. Catheterization and Cardiovascular Interventions, 70, 900-903. http://dx.doi.org/10.1002/ccd.21271

[10] Berman, D.P., Khan, D.M., Gutierrez, Y. and Zahn, E.M. (2012) The Use of Three-Dimensional Rotational Angiography to Assess the Pulmonary Circulation Following Cavo-Pulmonary Connection in Patients with Single Ventricle. Catheterization and Cardiovascular Interventions, 80, 922-930. http://dx.doi.org/10.1002/ccd.23461

[11] De Buck, S., Alzand, B.S., Wielandts, J.Y., Garweg, C., Phlips, T., Ector, J., Nuyens, D. and Heidbuchel, H. (2013) Cardiac Three-Dimensional Rotational Angiography Can Be Performed with Low Radiation Dose While Preserving Image Quality. Europace, 15, 1718-1724. http://dx.doi.org/10.1093/europace/eut140

[12] Fagan, T.E., Truong, U.T., Jone, P.N., Bracken, J., Quaife, R., Hazeem, A.A., Salcedo, E.E. and Fonseca, B.M. (2014) Multimodality 3-Dimensional Image Integration for Congenital Cardiac Catheterization. Methodist DeBakey Cardiovascular Journal, 10, 68-76. http://dx.doi.org/10.14797/mdcj-10-2-68

[13] Kabra, R. and Singh, J. (2010) Recent Trends in Imaging for Atrial Fibrillation Ablation. Indian Pacing and Electrophysiology Journal, 10, 215-227.

[14] Patel, B., Coyle, J., Poe, E., Rosenbloom, C., Stevens, R., Coren, J., Ge, S., Mesia, I., Moulick, A. and Toib, A. (2013) Three Dimensional Rotational Angiography Imaging of Double Aortic Arch Vascular Ring. Images in Paediatric Cardiology, 15, 1-6.

[15] Manica, J.L., Borges, M.S., Medeiros, R.F., Fischer Ldos, S., Broetto, G. and Rossi Filho, R.I. (2014) A Comparison of Radiation Dose between Standard and 3D Angiography in Congenital Heart Disease. Arquivos Brasileiros de Cardiologia, 103, 131-137. http://dx.doi.org/10.5935/abc.20140118

[16] Rivera, T. (2012) Thermoluminescence in Medical Dosimetry. Applied Radiation and Isotopes, 71, 30-34. http://dx.doi.org/10.1016/j.apradiso.2012.04.018

[17] International Commission on Radiological, P. (2004) Annals of the ICRP. A Report of: Doses to Infants from Ingestion of Radionuclides in Mothers' Milk. Annals of the ICRP, 34, iii, 15-267, 269-280.

[18] Glockler, M., Koch, A., Greim, V., Shabaiek, A., Ruffer, A., Cesnjevar, R., Achenbach, S. and Dittrich, S. (2011) The Value of Flat-Detector Computed Tomography during Catheterisation of Congenital Heart Disease. European Radiology, 21, 2511-2520. http://dx.doi.org/10.1007/s00330-011-2214-3

[19] Peters, M., Krings, G., Koster, M., Molenschot, M., Freund, M.W. and Breur, J.M. (2015) Effective Radiation Dosage of Three-Dimensional Rotational Angiography in Children. Europace, 17, 611-616. http://dx.doi.org/10.1093/europace/euu207

[20] Durand, S. and Paul, J.F. (2014) Comparison of Image Quality between $70 \mathrm{kVp}$ and $80 \mathrm{kVp}$ : Application to Paediatric Cardiac CT. European Radiology, 24, 3003-3009. http://dx.doi.org/10.1007/s00330-014-3341-4

[21] Wielandts, J.Y., De Buck, S., Michielsen, K., Louw, R., Garweg, C., Nuyts, J., Ector, J., Maes, F. and Heidbuchel, H. (2015) Multi-Phase Rotational Angiography of the Left Ventricle to Assist Ablations: Feasibility and Accuracy of Novel Imaging. European Heart Journal. (Published Online) 


\section{Abbreviations and Acronyms}

$3 \mathrm{D}$

three dimensional

30/5s DR-L low dose program

30/5s DRc diagnostic dose program

CT computed tomography

MRI magnetic resonance imaging

TEE transesophageal echocardiography

\section{Submit or recommend next manuscript to SCIRP and we will provide best service for you:}

Accepting pre-submission inquiries through Email, Facebook, LinkedIn, Twitter, etc.

A wide selection of journals (inclusive of 9 subjects, more than 200 journals)

Providing 24-hour high-quality service

User-friendly online submission system

Fair and swift peer-review system

Efficient typesetting and proofreading procedure

Display of the result of downloads and visits, as well as the number of cited articles

Maximum dissemination of your research work

Submit your manuscript at: http://papersubmission.scirp.org/ 